\title{
COLÓQUIOS RECENTES DE CLIMATOLOGIA
}

MARIA JOÃO ALCOFORADO ${ }^{1}$

Pretende-se dar breve notícia sobre quatro colóquios recentemente organizados por dois grupos internacionais, que integram investigadores da área da Climatologia e das Ciências vizinhas, e nos quais Portugal se encontra representado.

No quadro da União Geográfica Internacional (UGI) funciona, de há alguns anos para cá, a Comissão de Climatologia. O seu primeiro presidente foi o Professor $M$. Yoshino, da Universidade de Tsukuba (Japão). A Comissão foi precedida por três grupos de trabalho, orientados para os seguintes temas: variações climáticas, climatologia tropical e cartografia topoclimática. Em 1992, na reunião que teve lugar em State College (Pennsylvania, Estados Unidos da América), o Professor M. Domroes, da Universidade de Mainz (Alemanha) sucedeu ao Professor Yoshino, como presidente da Comissão. Este é apoiado por 10 Full Members e por grande número de Corresponding Members.

A Comissão reúne, regularmente, de dois em dois anos, nas ocasiões dos Congressos Internacionais e das Conferências Regionais da UGI. Em 1994, a Comissão reuniu em Brno (República Checa), na semana precedente à do Colóquio da UGI de Praga. A próxima reunião está prevista para Haia, em Agosto de 1996, e a seguinte terá provavelmente lugar em Lisboa, em 1998. Nos anos ímpares, ocorrem por vezes outros colóquios intercalares, como o de Mendoza (Argentina) de que se dará aqui conta.

Pelo seu lado, a Associação Internacional de Climatologia (AIC), fundada em 1988, agrupa mais de uma centena de investigadores (geógrafos, meteorologistas, físicos, etc.). das mais diversas nacionalidades De momento, o seu presidente é grego: Panagiotis MAHERAS, professor no Instituto de Meteorologia e Climatologia da Universidade de Salónica. A AIC é gerida por uma Comissão de Administração, composta por 12 membros. Segundo os estatutos, a AIC tem por principal objectivo o estreitamento de laços de cooperação entre cientistas de todo o Mundo, através da promoção de trocas de informação sobre os estudos recentes em Climatologia, de actividades científicas comuns aos seus membros, de reuniões e colóquios e da publicação de trabalhos científicos. A AIC organiza todos os anos um Colóquio Internacional sobre temas diversos (variabilidade temporal e espacial dos climas, sua cartografia, seus processos e seus mecanismos, aplicabilidade da Climatologia, etc.), em diferentes países (de 1988 a 1995 nos seguintes locais: Aix-en-Provence, Pavia, Lanion, Friburgo/Suíça, Dijon, Salónica, Toulouse, Liège). Nas Publications de l'Association Internationale de Climatologie, agrupam-se anualmente artigos sobre os temas das comunicações e posters apresentados nos Colóquios, desde que revistos e aceites pela Comissão de Redacção.

Nos Verões de 1994 e de 1995, realizaram-se quatro importantes reuniões de Climatologia, duas no quadro da União Geográfica Internacional (em Brno e em Mendoza) e outras duas organizadas pela Associação Internacional de Climatologia (em Toulouse e em Liège).

$1-1994$

1.1 - Colóquio de Brno (Comissão de Climatologia, UGI) 1 Professora Associada da Universidade de Lisboa. Centro de Estudos Geográficos da Universidade de Lisboa.
Faculdade de Letras. 1699 Lisboa Codex. Fax: (351-1) 79300 63, e-mail:mjalcoforado@ mail.telepac.pt 
Em Brno, na República Checa, de 15 a 21 de Agosto de 1994, teve lugar um Simpósio Internacional sobre Climatologia Contemporânea, precedendo a Conferência Regional de Geografia de Praga, onde uma sessão foi igualmente dedicada a temas de Climatologia. A organização esteve a cargo do Professor Rudolf Brázdil, da Universidade de Masarik. Participaram 130 cientistas de diversas disciplinas (Geografia, Geofísica, Meteorologia, Hidrologia, Física e Química da Atmosfera, entre outras), de variadas nacionalidades.

Foram apresentadas cerca de 90 comunicações, tendo decorrido várias sessões paralelas, que alternaram com duas outras de posters. A conferência concluiu-se com duas excursões: uma através da Morávia do Sul, em que foram focados os problemas ecológicos decorrentes da construção de uma grande barragem; a segunda teve lugar nos arredores da cidade de Brno, e incluiu a visita de paisagens de karst e de monumentos diversos.

Os principais temas em debate foram a variabilidade e as mudanças climáticas. Uma das tarefas consideradas prioritárias foi o desenvolvimento da investigação no sentido de detectar as variações climáticas, uma vez que as oscilações e as tendências climáticas continuam ainda incompletamente entendidas. Este facto explicaria a relutância das nações em desenvolver uma política conducente à efectiva redução do aumento de gases ditos de estufa, no nosso planeta. Aliás, um dos objectivos da Comissão de Climatologia é o de "dar directrizes no sentido da redução da incerteza nas previsões das variações climáticas e dos seus possíveis impactes."2

Merecem igualmente referência as discussões referentes à sobre-estimação do aumento da temperatura global, previsto uma década atrás. Alguns investigadores consideram o $\mathrm{SO}_{2}$ responsável por este facto. Como? Segundo cientistas de Environment Canada, citado por Nkemdirim ${ }^{3}$, este poluente altera a química das nuvens. A partir de amostras obtidas por aviões voando no interior daquelas, foi concluído que fortes concentrações em sulfatos produzem gotículas anormalmente pequenas, mas muito numerosas. Tais gotículas tenderiam a aumentar a radiação difusa, parte da qual é reenviada para o espaço, em detrimento da radiação directa. A diminuição da radiação global contribuiria para o abaixamento da temperatura na baixa troposfera, pelo menos durante o dia. É um facto já empiricamente comprovado que a temperatura máxima média não tem sofrido grandes modificações no Hemisfério Norte onde, pelo contrário, a temperatura mínima tem aumentado. Verificando-se esta hipótese, a presença de uma atmosfera poluída por sulfatos contribuiria para a diminuição das temperaturas diurnas.

Outras comunicações visaram a importância do estudo da homogeneidade das séries temporais de dados climáticos e a dificuldade crescente de acesso aos dados de base, por parte dos investigadores universitários. A Comissão ficou de chamar a atenção da Organização Meteorológica Mundial para tal facto, sugerindo uma política internacional que assegure mais fácil e menos oneroso acesso à informação meteorológica.

\section{2 - Colóquio de Toulouse (AIC)}

De 14 a 16 de Setembro de 1994, realizou-se a sétima reunião da Associação Internacional de Climatologia, em Toulouse, tendo sido a Société Météorologique de France (Météo-France) a Instituição anfitriã e os reponsáveis, os Drs. P. Galzi e Marc Payen.

O Colóquio de Toulouse permitiu a reunião de 158 investigadores de 24 nacionalidades e de 4 continentes, que apresentaram 82 comunicações e 10 posters. Os temas principais voltavam a estar relacionados com as variações climáticas do último

\footnotetext{
2 Climate Digest, vol. 4, nº 3, 1994.

3 Climate Digest, vol. 4, no 3, 1994
} 
século. Portanto, um mês depois da conferência de Brno, as variações climáticas eram novamente tema de acessas discussões. No Colóquio de Toulouse foram apresentados bastantes trabalhos monográficos, tanto referentes às regiões temperadas (Atlântico Norte e Oriental, França, Canadá), como a regiões tropicais (Nordeste do Brasil, Sahel, Senegal, Mali, Sudão). Os resultados de estudos levados a cabo a partir de elementos climáticos medidos nas estações meteorológicas são indispensáveis para que, pouco a pouco, se vá acumulando informação fiável sobre as variações climáticas regionais; aquela permitirá matizar as conclusões avançadas por grupos que trabalham sobre o global change.

A Météo-France teve a seu cargo várias comunicações, dando a conhecer a sua investigação recente e a criação de novas redes de estações meteorológicas automáticas, mais densas. Foram igualmente divulgadas as técnicas de verificação das bases de dados e de interpolação espacial, utilizando, como complemento, informação proveniente da teledetecção e de radares meteorológicos.

A climatologia aplicada foi tema de seis apresentações. Foram focadas as relações entre o clima, o solo e a vegetação em vários locais do globo, incluindo Portugal. Vinte e sete estudos regionais do clima, com destaque para as regiões mediterrâneas, temperadas e tropicais foram expostos em três sessões. Alguns autores desenvolveram mais a explicação das características climáticas descritas, nomeadamente pela dinâmica atmosférica; outros deram mais relevo às consequências do clima, focando os riscos climáticos de uma maneira geral, ou as consequências muito particulares de quedas de neve, episódios de geada, ou de precipitações intensas, numa perspectiva aplicada. A climatologia local ou topoclimatologia foi alvo de sete comunicações, referentes ao ambiente urbano ou a áreas de topografia movimentada. Métodos e técnicas de observação e de interpolação em climatologia local foram confrontados, resultados obtidos foram objecto de discussão.

Saliente-se a comunicação muito original de A. Hufty (Canadá, ex-presidente da AIC), ao mesmo tempo de Lexicologia e de Climatologia, sobre o vocabulário empregue em mais de 1000 referências, na bibliografia climatológica em língua francesa, entre 1988 e 1992. O autor parte de um estudo estatístico sobre a utilização e a associação de palavras, para uma reflexão mais profunda sobre o presente e o futuro da Climatologia. A análise da ocorrência de palavras-chave e da frequência das respectivas co-ocorrências permitiu caracterizar os temas de principal interesse. Foram dados numerosos exemplos, tendo sido demonstrado que alguns estudos, nomeadamente os aplicados, são feitos em colaboração com outras disciplinas vizinhas. A comunicação terminou de modo optimista: salientou-se a utilidade da Climatologia e o importante papel de síntese que os geógrafos podem ter.

O colóquio encerrou-se com uma excursão a Carcassone.

$2-1995$

\section{1 - Colóquio de Mendoza (Comissão de Climatologia, UGI)}

Em Mendoza (Argentina), de 13 a 27 de Agosto de 1995, teve lugar outra reunião sob o auspício da União Geográfica Internacional e em que participaram cerca de 60 pessoas. Iniciou-se por um Colóquio Internacional que durou seis dias, e por um workshop. Este constou de uma aplicação prática de diversas técnicas de medições itinerantes e de lançamentos de balões cativos, assim como de visitas a postos fixos de medição de poluição do ar. Este trabalho de três dias prosseguiu com uma excursão de uma semana no NW da Argentina.

O organizador local foi o Professor Raul Mikkan, do Departamento de Geografia da Universidade de Cuyo, estando incluídos na Comissão Científica, entre outros, os 
Professores Heinz Wanner, da Universidade de Berna, e o Professor Wilfried Endlicher da Universidade de Marburg (Alemanha).

Os temas centrais do Colóquio foram a poluição do ar, a climatologia urbana, o clima das montanhas, a climatolgia regional e os impactes locais e regionais das variações climáticas, num total de cerca de 30 comunicações e de 4 conferências.

Os dois primeiros temas estão muito intimamente correlacionados. De climatologia urbana, citem-se os trabalhos monográficos apresentados sobre Madrid, Buenos Aires e Friburgo (Alemanha), além de uma interessante, se bem que ainda polémica contribuição canadiana (L.Nkemdirim): apresentou-se a tese de que a intensidade da ilha de calor urbana tende a diminuir devido ao aumento global de temperatura mínima, a partir de dados concretos relativos à cidade de Calgary. Para esta cidade, os números são esclarecedores. O que se passará nas outras?

Nas comunicações agrupadas no tema "Poluição do ar" relacionaram-se as condições de ventilação com as emissões (quando conhecidas) e com as imissões. Ouviu-se falar novamente de Madrid e de Buenos Aires, de vários locais da Suíça, de Santiago do Chile, de Graz (Austria), Concepción, e da Polónia. Muitas conclusões são comparáveis: o ritmo diurno da concentração dos poluentes, com dois picos às horas de maior tráfego e a variabilidade daquela com a estrutura térmica vertical da atmosfera, por exemplo. Alguns autores insistiram mais nos desenvolvimentos metodológicos ou nos modelos para a simulação de episódios de smog (especialmente a escola de Berna), outros na apresentação e interpretação de situações concretas.

O tema "O Clima e o Tempo nas Montanhas", tão importante para uma cidade como Mendoza, na base dos Andes, foi não só tratado a partir de exemplos locais, mas também das Montanhas Rochosas e dos Alpes. Foi referida a influência das cadeias montanhosas na deflecção horizontal e vertical do fluxo, o seu efeito de atrito, o seu papel no fornecimento de fontes de calor latente e de calor sensível. Os ventos de causas predominantemente térmicas foram igualmente alvo de apresentação oral.

As comunicações agrupadas nos temas "Climatologia regional e local" foram bastantes diferenciadas: nalgumas partiu-se das condições climáticas para se proceder à avaliação ecológica de um determinada área (por exemplo, a Patagónia) ou para se efectuarem estudos de impactes. Noutras, os padrões térmicos foram determinados a partir de imagens NOAA/AVHRR (Chile, Portugal). Podem citar-se também algumas intervenções sobre climas locais, de que destacamos uma classificação de padrões de vento junto a Biel (Suíça).

Certos participantes debruçaram-se sobre os impactes das variações climáticas. Cita-se, a título de exemplo, um trabalho sobre a vulnerabilidade das áreas costeiras à subida prevista do nível do mar, e outro que relaciona as mudanças da ocupação do solo com o aumento de certos riscos climáticos.

O workshop foi particularmente interessante. Compararam-se aparelhos, métodos de aferição e diferentes técnicas, utilizadas pelos participantes: alguns com muitos anos de experiência neste domínio, outros principiantes, razão de sobra para que esta troca de informação e de impressões tenha sido muito proveitososa para todos. Iniciava-se, em Agosto de 1995, um projecto germano-argentino sobre o clima urbano de Mendoza, cidade com características climáticas muito particulares, uma vez que se trata de um dos oásis na base dos Andes e a uma latitude próxima do pico do Aconcágua (6650metros de altitude), onde aliás o grupo se deslocou. Seguiram-se todos os passos do início de um estudo de Climatologia Urbana: escolha dos pontos de observação fixos e itinerantes, percursos de observação a várias horas do dia e da noite, etc., rematados pelas análise, discussão e apresentação dos primeiros resultados.

A excursão ao NW da Argentina foi interessantíssima uma vez que permitiu visitar, em pouco mais de uma semana, várias regiões morfo-fito-climáticas e obser- 
var o escalonamento em altitude das formas, do clima e da vegetação. Não se fará uma descrição dessa viagem, mas saliente-se o interesse de, num mesmo dia, ao subir a vertente oriental dos Andes, se passar por uma floresta tropical, pela puna, até se chegar a áreas desérticas, onde foram visitadas ruínas Incas. Refira-se igualmente a beleza rude do deserto em Valle de la Luna (15\% de humidade relativa) e dos altiplanos salgados, assim como a imensidão do País, conhecida previamente decerto através dos dados numéricos, mas só efectivamente apreendida depois de se terem percorrido, numa semana, cerca de $1400 \mathrm{~km}$, e apenas se ter visitado o extremo NW da Argentina, até próximo da fronteira com a Bolívia. Interessantes contactos com as populações tiveram lugar em feiras e mercados; outros, menos genuínos, ocorreram em paragem turísticas dos autocarros, onde mesmo as crianças já sabem reclamar o preço da fotografia que lhe é tirada junto ao seu lama!

\section{2 - Colóquio de Liège (AIC)}

De 6 a 9 de Setembro de 1995, o oitavo Colóquio Anual da AIC desenrolou-se em Liège, Bélgica, tendo os cerca de 120 congressistas sido acolhidos no Departamento de Geografia Física pelo Professor Michel Erpicum, Presidente da Comissão Organizadora. Foram apresentados cerca de 80 comunicações e posters.

Retomou-se, em Liège, a discussão sobre o tema das variações climáticas (20 comunicações e posters). Voltou a suscitar particular interesse o original trabalho de André Hufty, desta vez sobre a "mensagem" referente às variações climáticas, veiculada na imprensa do Québec, entre 1985 e 1993: segundo o autor, os jornais dramatizam a questão climática, "martelando" alguns temas, com vocabulário restrito. As noções de variabilidade dos climas ou da adaptação regional aos extremos climáticos são ocultadas pelas notícias do aquecimento inelutável do clima mundial, que conduzirá a consequências verdadeiramente temíveis. No entanto, à medida que os anos passam, as notícias sobre o "catastrofismo" parecem ceder o lugar de destaque à incerteza quanto ao futuro climático.

A variabilidade espaço-temporal das mudanças climáticas, a que André Hufty se referiu, foi evidenciada nalgumas comunicações sobre a antiga URSS (estudada em comparação com a América do Norte), o Mediterrâneo Oriental, a Europa Central, o Índico e a África Oriental. Aquecimento, variabilidade da precipitação e da espessura da cobertura de neve não ocorrem simultaneamente em todos os locais, da mesma maneira que é grande a variabilidade climática regional, em parte devido aos diversos padrões de circulação a que cada área está submetida, nas várias épocas do ano. Mesmo num país de pequenas dimensões como Portugal, a sucessão de anos secos e de anos húmidos é diferente no Norte e no Sul, devido a causas relacionadas com a dinâmica atmosférica. O Institut Royal Météorologique de Belgique participou no Colóquio através da apresentação de técnicas para o estudo de séries temporais longas, com o objectivo de identificar heterogeneidades ou, num período homogéneo, de detectar mudanças climáticas.

As onze contribuições englobadas no tema de topoclimatologia tiveram um interesse não só teórico, mas também aplicado. Cite-se, como exemplo, um trabalho ( $\mathrm{S}$. Bridier et al.) em que se pretende avaliar o impacto do aterro que será construído para a futura linha do TGV (Train Grande Vitesse), numa zona de cultura de vinha, destinada à produção de "vin de Champagne". Foi feito um estudo experimental, construindo um obstáculo com as mesmas dimensões de um troço do aterro. Verificou-se que, impossibilitada a drenagem de ar frio ao longo de certas vertentes, se originavam os chamados "lagos de ar frio" que danificavam a vinha, podendo este prejuízo ser traduzido numa diminuição do rendimento. São apresentadas soluções 
alternativas (como a criação de aberturas no aterro, ou mesmo a construção de viadutos, em áreas mais sensíveis). Noutras comunicações, os autores referiram-se à circulação do vento em áreas de topografia movimentada e às suas relações com a qualidade do ar. O clima no planeamento urbanístico foi também tratado, nomeadamente na quantificação da obstrução do horizonte em canyons urbanos e sua influência no balanço radiativo. Uma comunicação de membros do Laboratório de Climatologia e Topoclimatologia de Liège, visava a determinação da temperatura superficial das estradas da região, em diversos tipos de tempo, para integração num sistema de prevenção de riscos de ocorrência de situações perigosas para os automobilistas. A aplicabilidade de um estudo deste tipo é evidente.

Uma parte substancial dos estudos de climatologia regional (28 comunicações e posters) estava orientada para a aplicação: na agricultura (citem-se os estudos de geadas na Tunísia e na Roménia), na prevenção de incêndios florestais (2 comunicações sobre o Sul da França e outra sobre a Bélgica onde, ao contrário do que se poderia pensar, também há incêndios, nomeadamente no mês de Maio). Para o SE da França, foi apresentado por P. Carrega um método de identificação automática, e em tempo real, do regime do vento, durante a época dos fogos florestais, para permitir um mais rápido e mais eficaz combate às chamas. Também para o SE da França, foi feita, por outros autores, a avaliação da evolução espaço-temporal dos riscos de fogos florestais, a partir de imagens de satélite.

De entre algumas comunicações, mais orientadas para a agricultura, cite-se o estudo apresentado por A.Bekkaoui, que descreveu, de forma muito clara, um modelo de previsão das condições de crescimento de uma planta numa estufa, em função das variáveis climáticas externas, estabelecendo assim relações quantitativas entre o macroclima e o microclima. Este modelo pode ser utilizado para o desenvolvimento de um sistema de gestão e de controle do microclima das estufas.

A análise dos temas tratados mostra que a comunidade científica está bastante preocupada com a problema das variações do clima e que tenta, por todos os meios ao seu alcance, contribuir para um mais profundo conhecimento das mudanças climáticas regionais. Será assim possível matizar certos resultados disponíveis sobre as variações do clima na escala planetária, de que outros grupos se ocupam (por exemplo, $o$ Intergovernmental Panel on Climate Change, em que aliás se inclui um Full Member da Comissão de Climatologia). Seria útil divulgar certas conclusões junto do grande público, para o consciencializar dos problemas ambientais, e orientar certos comportamentos individuais ou colectivos, embora evitando alarmismos desnecessários, fomentados, por vezes, pelos meios de comunicação social.

Nota-se, igualmente, que se numerosos autores continuam os estudos monográficos nas escalas regional e local, muitos o fazem numa perspectiva aplicada. É evidente também que os meios técnicos têm evoluído, sendo numerosos os trabalhos baseados em imagens de satélite ou de radares meteorológicos, a utilização de meios informáticos mais sofisticados, incluindo o uso dos Sistemas de Informação Geográfica, que hoje já é possível utilizar com reduzida capacidade finaneira.

A qualidade do ar e o clima das cidades parecem sobretudo uma preocupação do grupo da UGI, que se exprime em língua inglesa, enquanto no seio da AIC, em que a língua de trabalho é o francês, aparecem numerosas e interessantes contribuições sobre o continente africano, fruto de contactos que permanecem com as ex-colónias da França.

Nota-se também que, nas diversas reuniões, tanto da UGI como da AIC, em que o corpo dirigente é fundamentalmente constituído por geógrafos, há participação de 
meteorologistas (mesmo na organização de reuniões, como em Toulouse), de físicos e de outros investigadores de ciências afins. Este facto contribuirá certamente para um enriquecimento mútuo e para o mais rápido desenvolvimento da ciência que nos ocupa. 